Check for updates

Cite this: RSC Adv., 2017, 7, 30588

Received 18th May 2017

Accepted 7th June 2017

DOI: $10.1039 / c 7 r a 05635 d$

rsc.li/rsc-advances

\section{Photoluminescence properties of a novel red fluoride $\mathrm{K}_{2} \mathrm{LiGaF}_{6}: \mathrm{Mn}^{4+}$ nanophosphor ${ }^{+}$}

\author{
Yiwen Zhu, ${ }^{a}$ Jinbo Yu, ${ }^{a}$ Yong Liu, ${ }^{a}$ Mikhail G. Brik, ${ }^{\text {bcd }}$ Lin Huang, ${ }^{a}$ Tongtong Xuan (D) a \\ and Jing Wang $\mathbb{D}$ *a
}

Red $\mathrm{K}_{2} \mathrm{LiGaF}_{6}: \mathrm{Mn}^{4+}$ phosphors have been synthesized by the facile cation-exchange method. To optimize the optical properties, the phosphors were synthesized by using different reaction conditions. The highest luminescence intensity was increased 3.6 times for the $\mathrm{Mn}$ concentration of $1 \%$, reaction temperature of $20{ }^{\circ} \mathrm{C}$, and reaction time of $1 \mathrm{~h}$. Replacement of the trivalent Al by Ga resulted in $\mathrm{K}_{2} \mathrm{LiGaF}_{6}: \mathrm{Mn}^{4+}$ having better photoluminescence properties than $\mathrm{K}_{2} \mathrm{LiAlF}_{6}: \mathrm{Mn}^{4+}$. Furthermore, the studies of the temperaturedependent emission intensity of the phosphors confirmed their good thermal stability, making them promising red phosphor candidates for white light-emitting diodes.

\section{Introduction}

White light-emitting diodes (LEDs) have attracted considerable attention as an energy-saving light source for a long time. ${ }^{\mathbf{1 - 6}}$ Commercial white LEDs fabricated by a blue LED chip with a yellow YAG:Ce ${ }^{3+}$ phosphor still suffer from some drawbacks such as low color rendering index $(\mathrm{Ra}<80)$ and high correlated color temperature (CCT $>6000 \mathrm{~K}$ ) because of the lack of a red light component. ${ }^{-9}$ So, great efforts have been made to make appropriate red phosphors. Currently most of the available red phosphors still have certain problems. ${ }^{\mathbf{1 0 , 1 1}}$ For example, oxide phosphors ${ }^{12-16}$ cannot absorb blue light efficiently and sulfide phosphors ${ }^{17-19}$ are unstable because of their high sensitivity to hydrolysis reactions. As for the nitride phosphors, ${ }^{20-23}$ they have overlapping re-absorption with the yellow phosphor and the synthesis conditions are rigid. Hence, it is very urgent to find a new red phosphor that can efficiently absorb blue light and has small overlap with the emission of the YAG: $\mathrm{Ce}^{3+}$ phosphor. The $\mathrm{Mn}^{4+}$ doped fluoride red phosphors ${ }^{24-30}$ have been widely investigated in recent years. Their main advantage is that they can absorb near ultraviolet and blue light to produce narrowband red emission with broad prospects to be used for white LEDs.

\footnotetext{
${ }^{a}$ School of Chemistry, Sun Yat-sen University, No. 135, Xingang Xi Road, Guangzhou, 510275, P. R. China.E-mail: ceswj@mail.sysu.edu.cn

${ }^{b}$ College of Mathematics and Physics, Chongqing University of Posts and Telecommunications, 2 Chongwen Road, Nan'an District, Chongqing 400065, P. R. China

${ }^{c}$ Institute of Physics, University of Tartu, W. Ostwald Str. 1, Tartu 50411, Estonia ${ }^{d}$ Institute of Physics, Jan Dlugosz University, Armii Krajowej 13/15, PL-42-201, Czestochowa, Poland
}

$\dagger$ Electronic supplementary information (ESI) available. See DOI: 10.1039/c7ra05635d
Recently, the $\mathrm{Mn}^{4+}$-doped fluoride phosphors $\mathrm{A}_{2} \mathrm{MF}_{6}: \mathrm{Mn}^{4+}$ (A $\left.=\mathrm{Na}, \mathrm{K}, \mathrm{Rb}, \mathrm{Cs},\left(\mathrm{NH}_{4}\right), \mathrm{M}=\mathrm{Si}, \mathrm{Ti}, \mathrm{Ge}, \mathrm{Sn}, \mathrm{Zr}\right)^{31-38}$ and $\mathrm{BMF}_{6}: \mathrm{Mn}^{4+}(\mathrm{B}=\mathrm{Ba}, \mathrm{Zn}, \mathrm{M}=\mathrm{Si}, \mathrm{Ti}, \mathrm{Ge})^{39-45}$ were reported. Some of them show high quantum efficiency, thermal stability against quenching and so on. ${ }^{46}$ Recently, we had reported a red phosphor $\mathrm{K}_{2} \mathrm{LiAlF}_{6}: \mathrm{Mn}^{4+},{ }^{47}$ which belongs to the elpasolite group of materials with a double perovskite structure. Though it has excellent thermal quenching behavior, the luminescence intensity is still not high enough. Therefore, it is an urgent task to improve its emission intensity to meet the requirements for various applications.

There are many reports ${ }^{\mathbf{4 8 , 4 9}}$ confirming that the $\mathrm{Al}^{3+}$ ions can be substituted by the $\mathrm{Mn}^{4+}$ ions as luminescent center because of similar effective ionic radius $(r=0.53 \AA)$ when coordination number $(\mathrm{CN})$ is six. Since both $\mathrm{Al}$ and Ga belong to the same IIIA group in the periodic table, it is believed that $\mathrm{Al}$ can be substituted by Ga to adjust the luminescence properties. Since the effective ionic radius of $\mathrm{Ga}^{3+}(r=0.62 \AA)$ is a little bigger than $\mathrm{Mn}^{4+}(r=0.53 \AA)$ at $\mathrm{CN}=6$, it is strongly expected that the $\mathrm{Mn}^{4+}$ ions substitute for the $\mathrm{Ga}^{3+}$ ions sites easier, compared to $\mathrm{Al}^{3+}$ ions. Moreover, there is no research on this material up to date, and this also prompts us to study it.

In this work, we successfully synthesized a $\mathrm{K}_{2} \mathrm{LiGaF}_{6}: \mathrm{Mn}^{4+}$ phosphor via a facile cation exchange method. By optimizing the synthesis conditions, we obtain the best sample. The structure, morphology, composition and temperaturedependent photoluminescence (PL) properties were investigated in details. The PL spectra of both $\mathrm{K}_{2} \mathrm{LiAlF}_{6}: \mathrm{Mn}^{4+}$ and $\mathrm{K}_{2}-$ $\mathrm{LiGaF}_{6}: \mathrm{Mn}^{4+}$ phosphor were compared together to verify the effect on PL properties by changing luminescent center ions. Finally, we fabricated a white LED using a blue LED chip combined with a yellow phosphor and $\mathrm{K}_{2} \mathrm{LiGaF}_{6}: \mathrm{Mn}^{4+}$ red phosphor. 


\section{Experimental}

\subsection{Preparation of $\mathrm{K}_{2} \mathrm{LiGaF}_{6}$}

$0.3447 \mathrm{~g} \mathrm{LiNO}_{3}$ and $1.0110 \mathrm{~g} \mathrm{KNO}_{3}$ were weighted and dissolved in $5 \mathrm{ml} 1 \mathrm{~mol} \mathrm{~L}^{-1} \mathrm{Ga}\left(\mathrm{NO}_{3}\right)_{3}$ solution. After stirring for 30 minutes, a transparent solution was obtained. HF (48\%) solution was dropped slowly to the solution under stirring. A white precipitate $\mathrm{K}_{2} \mathrm{LiGaF}_{6}$ was obtained and washed with deionized water for several times and dried at $70{ }^{\circ} \mathrm{C}$ for $12 \mathrm{~h}$.

\subsection{Preparation of $\mathrm{K}_{2} \mathrm{LiGaF}_{6}: \mathrm{Mn}^{4+}$}

$0.1344 \mathrm{~g}$ prepared $\mathrm{K}_{2} \mathrm{LiGaF}_{6}$ were weighted and added into $2 \mathrm{ml}$ $\mathrm{HF}(48 \%)$ solution contained $0.0012 \mathrm{~g} \mathrm{~K}_{2} \mathrm{MnF}_{6}$. After stirring for 30 minutes, the suspension was centrifuged and washed with acetone for several times. The $\mathrm{K}_{2} \mathrm{LiGaF}_{6}: \mathrm{Mn}^{4+}$ phosphor was prepared after dried at $70{ }^{\circ} \mathrm{C}$ for $12 \mathrm{~h}$.

\subsection{Fabrication of WLEDs}

WLEDs were fabricated by combining a blue LED chip (450$460 \mathrm{~nm}, 3.0-3.4 \mathrm{~V}, 350 \mathrm{~mA}$ ), yellow phosphor YAG: $\mathrm{Ce}^{3+}$ and $\mathrm{K}_{2} \mathrm{LiGaF}_{6}: \mathrm{Mn}^{4+}$ red phosphor. The phosphors were mixed with silicone thoroughly and coated on the surface of the chip to produce WLEDs.

\subsection{Characterization}

XRD patterns were recorded using powder X-ray diffraction (XRD, Rigaku D/MAX 2200 VPC) with $\mathrm{Cu} \mathrm{K} \alpha 1$ radiation $(\lambda=$ $1.5405 \AA$ ) at a scanning rate of $10^{\circ} \mathrm{min}^{-1}$ over a $2 \theta$ range from $10^{\circ}$ to $80^{\circ}$. The morphology of the as-prepared products was measured by SEM (FEI Quanta 400). Transmission electron microscopy (TEM), selected area electron diffraction (SAED) and elemental composition were obtained from an FEI Tecnai G2 Spirit. Photoluminescence excitation (PLE) and photoluminescence (PL) spectra were determined on an FSP920combined time resolved and steady-state fluorescence spectrometer (Edinburgh Instruments) with a $450 \mathrm{~W}$ xenon lamp as the excitation source. Electron paramagnetic resonance (EPR) analyses were measured on spectrometer (BRÜCKNER A300-1012) with frequency of $9.8 \mathrm{GHz}$ and attenuator of $30 \mathrm{~dB}$. The photoelectric properties of the white LED devices were measured by Labsphere LPS-100-0260 and Labsphere CDS2100.

\section{Results and discussion}

\subsection{Phase, structure and spectroscopic studies}

Fig. 1(a) shows the XRD patterns of $\mathrm{K}_{2} \mathrm{LiGaF}_{6}$ and $\mathrm{K}_{2} \mathrm{LiGaF}_{6}$ :$\mathrm{Mn}^{4+}$. The diffraction peaks of $\mathrm{K}_{2} \mathrm{LiGaF}_{6}: \mathrm{Mn}^{4+}$ can be indexed to the standard pattern of cubic phase $\mathrm{K}_{2} \mathrm{LiGaF}_{6}$ (PDF no. 22-1225) with a unit cell $a=b=c=7.97 \AA, \alpha=\beta=\gamma=90^{\circ}$ and the volume $V=506.3 \AA^{3}$. The main peaks located at $19.3^{\circ}, 31.8^{\circ}$ and $45.5^{\circ}$, corresponding to the (111), (220) and (400) reflections, respectively. The reaction can be expressed as follows:

$$
\begin{aligned}
\mathrm{LiNO}_{3} \text { (aq.) }+2 \mathrm{KNO}_{3} \text { (aq.) }+\mathrm{Ga}\left(\mathrm{NO}_{3}\right)_{3} \text { (aq.) } \\
+6 \mathrm{HF} \text { (aq.) }==\mathrm{K}_{2} \mathrm{LiGaF}_{6} \text { (s) }+6 \mathrm{HNO}_{3} \text { (aq.) }
\end{aligned}
$$
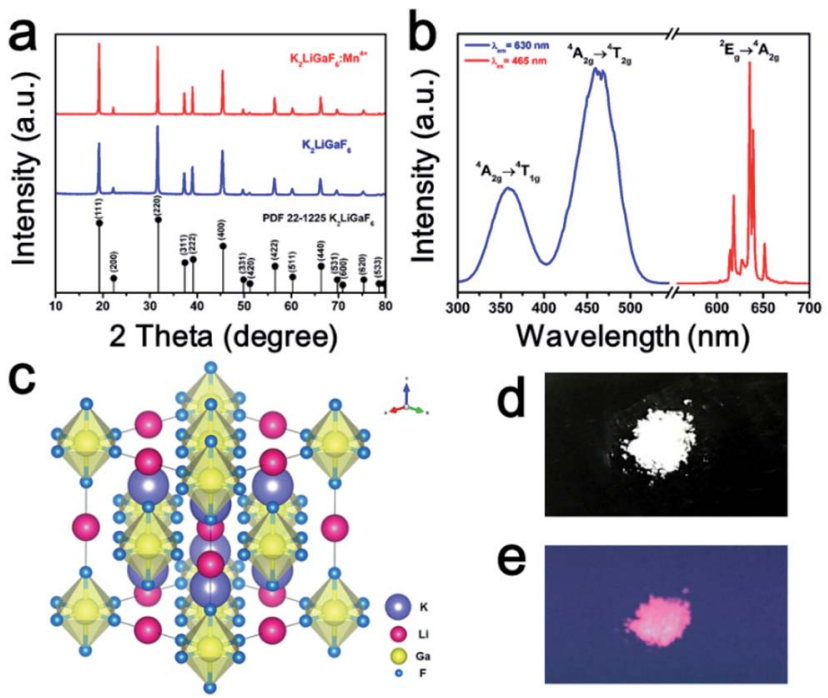

Fig. 1 (a) XRD patterns of $\mathrm{K}_{2} \mathrm{LiGaF}_{6}$ and $\mathrm{K}_{2} \mathrm{LiGaF}_{6}: \mathrm{Mn}^{4+}$, (b) PLE and PL spectra of $\mathrm{K}_{2} \mathrm{LiGaF}_{6}: \mathrm{Mn}^{4+}$, (c) structure diagram, (d) phosphor under natural light and (e) phosphor under UV-light.

When the nitrates are dissolved in the solution, the $\mathrm{F}^{-}$ anions bond the cations to form the $\mathrm{K}_{2} \mathrm{LiGaF}_{6}$ because of their strong ability of coordination. After the pure matrix phase is obtained, $\mathrm{Mn}^{4+}$ can be doped into it in the HF solution to form $\mathrm{K}_{2} \mathrm{LiGaF}_{6}: \mathrm{Mn}^{4+}$. Fig. 1(b) exhibits the photoluminescence excitations (PLE) and PL spectra of $\mathrm{K}_{2} \mathrm{NaGaF}_{6}: 1 \% \mathrm{Mn}^{4+}$. The PLE spectra contain two bands from $300 \mathrm{~nm}$ to $500 \mathrm{~nm}$, centered at $\sim 360 \mathrm{~nm}$ and $\sim 465 \mathrm{~nm}$ when monitored at $630 \mathrm{~nm}$. These two excitation bands are due to the ${ }^{4} \mathrm{~A}_{2 \mathrm{~g}} \rightarrow{ }^{4} \mathrm{~T}_{1 \mathrm{~g}}$ and ${ }^{4} \mathrm{~A}_{2 \mathrm{~g}} \rightarrow{ }^{4} \mathrm{~T}_{2 \mathrm{~g}}$ spin-allowed transitions of $\mathrm{Mn}^{4+}$. The phosphor emits a series of narrow band emission lines located at $610 \mathrm{~nm}, 614 \mathrm{~nm}$, $623 \mathrm{~nm}, 632 \mathrm{~nm}, 636 \mathrm{~nm}$ and $649 \mathrm{~nm}$, which are attributed to the spin-forbidden ${ }^{2} \mathrm{E}_{\mathrm{g}} \rightarrow{ }^{4} \mathrm{~A}_{2 \mathrm{~g}}$ transitions of $\mathrm{Mn}^{4+}$ and its vibronic sidebands, under $465 \mathrm{~nm}$ excitation. According to the group theory, the octahedral symmetry $O_{\mathrm{h}}$ has six fundamental internal vibronic modes, namely, $\mathrm{v}_{1}\left(\mathrm{~A}_{1 \mathrm{~g}}\right), \mathrm{v}_{2}\left(\mathrm{E}_{\mathrm{g}}\right), \mathrm{v}_{3}\left(\mathrm{~T}_{1 \mathrm{u}}\right), \mathrm{v}_{4}$ $\left(\mathrm{T}_{1 \mathrm{u}}\right), \mathrm{v}_{5}\left(\mathrm{~T}_{2 \mathrm{~g}}\right)$ and $\mathrm{v}_{6}\left(\mathrm{~T}_{2 \mathrm{u}}\right){ }^{46}$ The three peaks at longer than $623 \mathrm{~nm}$ wavelengths are ascribed to the Stokes $\mathrm{v}_{6}, \mathrm{v}_{4}$ and $\mathrm{v}_{3}$ peaks, and the two other peaks at shorter than $623 \mathrm{~nm}$ are the anti-Stokes $\mathrm{v}_{6}$ and $\mathrm{v}_{4}$ peaks. The peak at $623 \mathrm{~nm}$ is the zero phonon line (ZPL), which is the electric dipole forbidden in the octahedral $\left[\mathrm{MnF}_{6}\right]^{2-} .^{50}$ It has been reported that the ZPL emission intensity depends on the local symmetry of the $\mathrm{Mn}^{4+}$ ion. The higher the distortion of the octahedron, the stronger the ZPL emission intensity. ${ }^{51}$ The structure scheme and coordination environment of $\mathrm{K}_{2} \mathrm{LiGaF}_{6}$ are shown in Fig. 1(c). The $\mathrm{Ga}^{3+}$ ions and $\mathrm{Li}^{+}$ions are surrounded by $\operatorname{six~} \mathrm{F}^{-}$ions to form two types of octahedrons. The $\mathrm{K}^{+}$ions are at the center of a polyhedron formed by 12 neighbouring $\mathrm{F}^{-}$. The $\left[\mathrm{GaF}_{6}\right]^{3-}$ and $\left[\mathrm{LiF}_{6}\right]^{3-}$ octahedrons share corners in a network. The Ga-F bond length is $1.8419 \AA$, and the Li-F bond length is $2.1431 \AA$, with bond angles $\angle \mathrm{FGaF}=\angle \mathrm{FLiF}=90^{\circ}$. Since the effective ionic radius of $\mathrm{Mn}^{4+}(r=0.53 \AA)$ at $\mathrm{CN}=6$ is close to $\mathrm{Ga}^{3+}(r=0.62 \AA)$, the $\mathrm{Mn}^{4+}$ ions substitute for the $\mathrm{Ga}^{3+}$ ions sites. Because of the ionic radii and valence state mismatch, the octahedrons distort 
to some extent. The body color of phosphor is white under natural light and it emits red light under $365 \mathrm{~nm}$ UV-light, as shown in Fig. 1(d) and (e), respectively.

\subsection{Morphology and composition analysis}

Fig. 2(a) and (b) exhibit the SEM and TEM images of $\mathrm{K}_{2}$ $\mathrm{LiGaF}_{6}: \mathrm{Mn}^{4+}$. The SEM image shows that the as-synthesized sample consists of irregular aggregated particles with the size of about 100-200 $\mathrm{nm}$. The particle mean diameter is $67 \mathrm{~nm}$. This is different from other reported microscale $\mathrm{Mn}^{4+}$-doped fluoride phosphors. ${ }^{52-54}$ As shown in the inset of Fig. 2(b), the selected area electron diffraction (SAED) suggests that the samples are single crystals, of which the distinct diffraction dots can be indexed to the cubic phase $\mathrm{K}_{2} \mathrm{LiGaF}_{6}$. Fig. 2(c) shows the elemental composition analysis of $\mathrm{K}_{2} \mathrm{LiGaF}_{6}: \mathrm{Mn}^{4+}$ sample, which were quantitatively carried out by using energy dispersive spectrometer (EDS) to further prove the purity of the assynthesized sample. Li element is too light to be detected. It is clearly seen that $\mathrm{K}, \mathrm{Ga}, \mathrm{F}$ and $\mathrm{Mn}$ elements are included and for the reason of low Mn concentration, the Mn peaks are very weak. The atom percentages of $\mathrm{K}, \mathrm{Ga}$ and $\mathrm{F}$ are about $21.5 \%$, $11.6 \%$ and $52.8 \%$, respectively, which is almost close to $2: 1: 6$ ratio, i.e., the stoichiometric atom ratio of $\mathrm{K}_{2} \mathrm{LiGaF}_{6}$. These results further indicate that the as-obtained phosphor is in a pure phase.

\subsection{Room temperature PL properties}

To optimize the luminescence performance of $\mathrm{K}_{2} \mathrm{LiGaF}_{6}: \mathrm{Mn}^{4+}$, the effects of the nominal molar concentration of doped $\mathrm{Mn}^{4+}$, reaction time and reaction temperature were systematically investigated, as shown in Fig. S1-S3 in ESI. $\uparrow$ By adjusting the reaction conditions, the best sample $\mathrm{K}_{2} \mathrm{LiGaF}_{6}: 1 \% \mathrm{Mn}^{4+}$ was
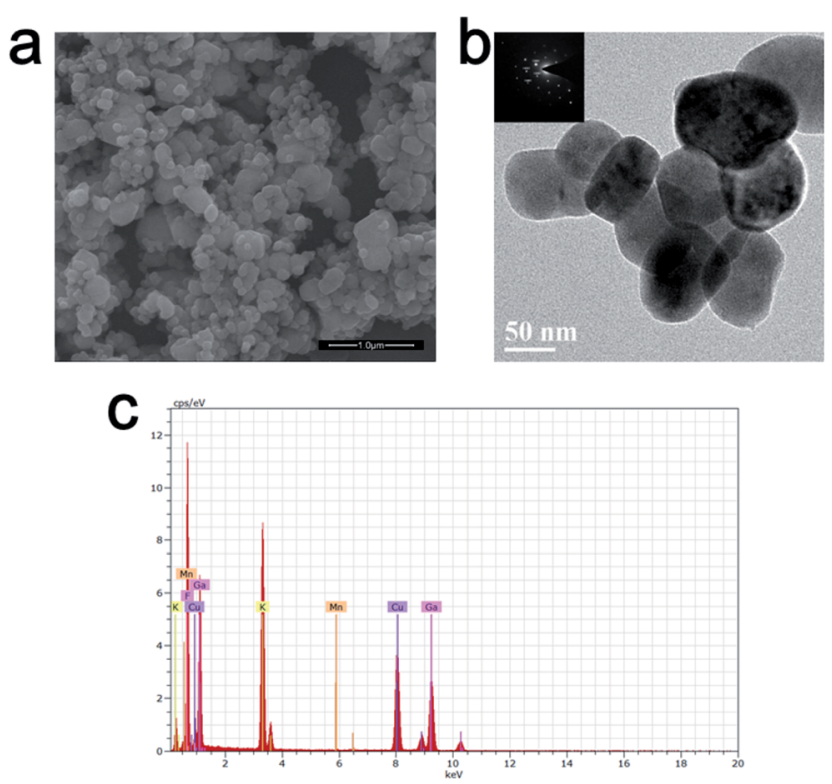

Fig. 2 (a) SEM and (b) TEM (the inset is SAED patterns of one particle) images and (c) quantitative elemental composition data of $\mathrm{K}_{2} \mathrm{LiGaF}_{6}: \mathrm{Mn}^{4+}$ obtained under $20{ }^{\circ} \mathrm{C}$ for $1 \mathrm{~h}$. In this way, the PL intensity can be increased 3.5 times.

The optimized phosphor shows much higher emission intensity than $\mathrm{K}_{2} \mathrm{LiAlF}_{6}: \mathrm{Mn}^{4+}$ (Fig. 3). We attribute this result to the considerable ionic radii difference between $\mathrm{Ga}^{3+}$ and $\mathrm{Al}^{3+}$. Since $\mathrm{Ga}^{3+}(r=0.62 \AA)$ is a little bigger than $\mathrm{Al}^{3+}(r=0.535 \AA)$, there is more space to be occupied by $\mathrm{Mn}^{4+}(r=0.53 \AA)$ at the $\mathrm{Ga}$ position. Such a large cavity - especially taken together with the difference of electric charges of $\mathrm{Mn}^{4+}$ and $\mathrm{Ga}^{3+}$ - would favour the off-center displacement of the $\mathrm{Mn}^{4+}$ ions. Such a displacement will lower the symmetry of the $\mathrm{MnF}_{6}$ octahedra by eliminating the inversion center. As a result, the PL intensity of $\mathrm{K}_{2} \mathrm{LiGaF}_{6}: \mathrm{Mn}^{4+}$ is much higher than that one of $\mathrm{K}_{2} \mathrm{LiAlF}_{6}: \mathrm{Mn}^{4+}$. To further prove the concentration of $\mathrm{Mn}^{4+}$ is higher in $\mathrm{K}_{2} \mathrm{LiGaF}_{6}$, we measure the EPR spectra of two phosphors with the same doping concentration in Fig. 3(b). The signal of $\mathrm{Mn}^{4+}$ ions in $\mathrm{K}_{2} \mathrm{LiGaF}_{6}$ host is six featured peaks, ${ }^{55}$ while it is much lower in $\mathrm{K}_{2} \mathrm{LiAlF}_{6}$. This indicates the concentration of $\mathrm{Mn}^{4+}$ ions is truly higher in $\mathrm{K}_{2} \mathrm{LiGaF}_{6}$ so that leads to higher emission intensity.

\subsection{Temperature-dependent PL properties}

The temperature-dependent emission spectra of $\mathrm{K}_{2} \mathrm{LiGaF}_{6}: \mathrm{Mn}^{4+}$ in the 300-500 $\mathrm{K}$ temperature range under $465 \mathrm{~nm}$ excitation are presented in Fig. 4(a). Apparently, there is no shift or broadening of the emission peaks but the intensity decreases gradually with the increasing temperature. Fig. 4(b) reveals this trend clearly. It can be seen that the emission intensity is almost the same in the temperature range from $300 \mathrm{~K}$ to $375 \mathrm{~K}$ and then drops sharply with the temperature above $400 \mathrm{~K}$. At $425 \mathrm{~K}(150$ ${ }^{\circ} \mathrm{C}$ ), it remains $88.8 \%$ of the initial intensity at $300 \mathrm{~K}$. Similar thermal quenching behavior of $\mathrm{Mn}^{4+}$ ion in fluoride phosphors had been reported for several times. ${ }^{\mathbf{4 9 5 6 , 5 7}}$ We determine the activation energy $\left(E_{\mathrm{a}}\right)$ of $\mathrm{K}_{2} \mathrm{LiGaF}_{6}: \mathrm{Mn}^{4+}$ for thermal quenching using eqn (1). ${ }^{58}$

$$
I_{T}=\frac{I_{0}}{1+A \exp \left(-\frac{E_{\mathrm{a}}}{k_{\mathrm{B}} T}\right)}
$$

where $I_{0}$ is the initial emission intensity, $I_{T}$ is the intensity at different temperatures, $E_{\mathrm{a}}$ is activation energy of thermal quenching, $A$ is a constant, and $k_{\mathrm{B}}$ is the Boltzmann constant $\left(8.617 \times 10^{-5} \mathrm{eV} \mathrm{K}^{-1}\right)$. Its value for $\mathrm{K}_{2} \mathrm{LiGaF}_{6}: \mathrm{Mn}^{4+}$ is about $0.24 \mathrm{eV}$, which is close to other fluoride phosphors we had
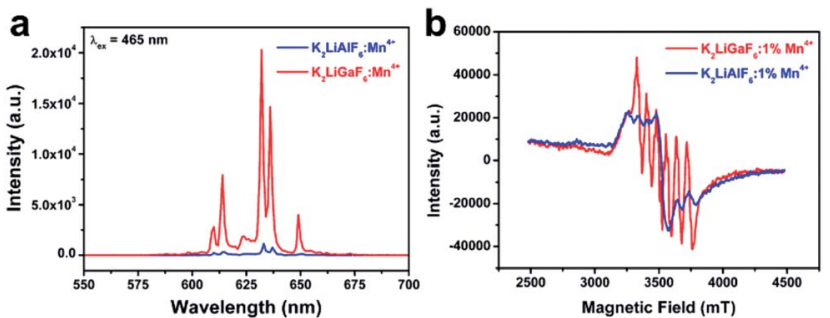

Fig. 3 (a) PL spectra and (b) EPR spectra of $\mathrm{K}_{2} \mathrm{LiAlF}_{6}: \mathrm{Mn}^{4+}$ and $\mathrm{K}_{2} \mathrm{LiGaF}_{6}: \mathrm{Mn}^{4+}$. 

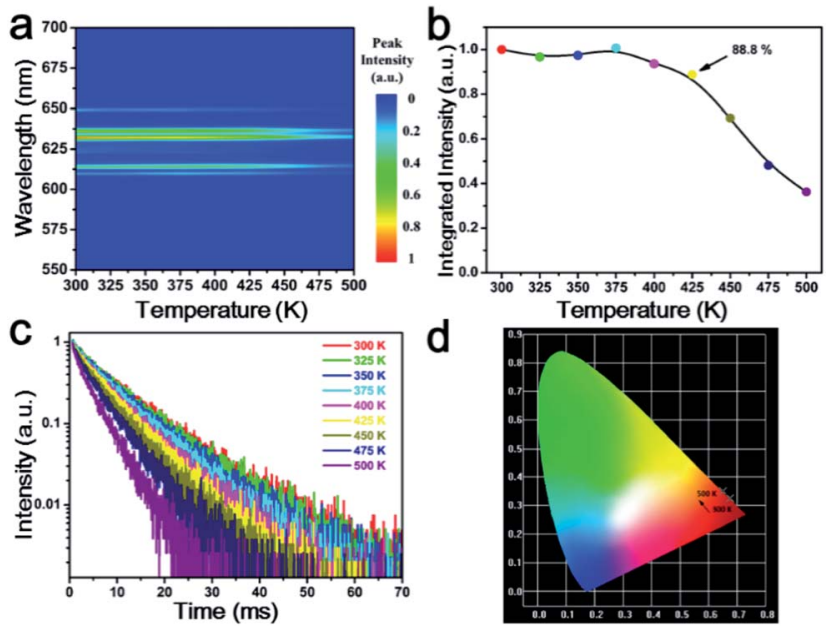

Fig. 4 (a) Temperature-dependent emission spectra of $\mathrm{K}_{2} \mathrm{LiGaF}_{6}$ :$\mathrm{Mn}^{4+}$ from $300 \mathrm{~K}$ to $500 \mathrm{~K}$, (b) PL integrated intensity, (c) decay time and (d) $\mathrm{ClE}$ chromaticity coordinates of $\mathrm{K}_{2} \mathrm{LiGaF}_{6}: \mathrm{Mn}^{4+}$ from $300 \mathrm{~K}$ to $500 \mathrm{~K}$.

reported before. ${ }^{47}$ The decay time of $\mathrm{K}_{2} \mathrm{LiGaF}_{6}: \mathrm{Mn}^{4+}$ in Fig. 4(c) shows that the luminescence intensity undergoes a rapid decrease from $300 \mathrm{~K}$ to $500 \mathrm{~K}$, which is due to the increase in the non-radiative transition probability at higher temperature. ${ }^{59}$ Therefore, the decay time becomes shorter with the increasing temperature. The CIE color coordinates of $\mathrm{K}_{2} \mathrm{LiGaF}_{6}: \mathrm{Mn}^{4+}$ change from $(0.675,0.325)$ to $(0.651,0.349)$ in the whole temperature range of 300-500 K (Fig. 4(d)). More CIE values can be found in Table S1 in ESI. $\uparrow$ Obviously, $\mathrm{K}_{2} \mathrm{LiGaF}_{6}: \mathrm{Mn}^{4+}$ shows small shift of color coordinates in the red region, which is mainly due to the tiny shift and broadening of sharp red emission peaks of $\mathrm{Mn}^{4+}$. This further suggests that $\mathrm{K}_{2} \mathrm{LiGaF}_{6}$ :$\mathrm{Mn}^{4+}$ shows excellent color stability. Moreover, the color purity of $\mathrm{K}_{2} \mathrm{LiGaF}_{6}: \mathrm{Mn}^{4+}$ calculated by eqn $(2)^{60}$ is about $94 \%$.

$$
\text { Color purity }=\frac{\sqrt{\left(x-x_{\mathrm{i}}\right)^{2}+\left(y-y_{\mathrm{i}}\right)^{2}}}{\sqrt{\left(x_{\mathrm{d}}-x_{\mathrm{i}}\right)^{2}+\left(y_{\mathrm{d}}-y_{\mathrm{i}}\right)^{2}}}
$$

where $(x, y)$ is the color coordinates of the phosphor, $\left(x_{\mathrm{i}}, y_{\mathrm{i}}\right)$ is the CIE of an equal-energy illuminant with a value of $(0.3333$, $0.3333)$, and $\left(x_{\mathrm{d}}, y_{\mathrm{d}}\right)$ is the chromaticity coordinates corresponding to the dominant wavelength of the light source.

\subsection{LED application}

Fig. 5(a) shows the current-dependent LED performance fabricated with a blue LED chip combined with the YAG:Ce ${ }^{3+}$ and $\mathrm{K}_{2} \mathrm{LiGaF}_{6}: \mathrm{Mn}^{4+}$ phosphors. The sharp peak located at about $450 \mathrm{~nm}$ belongs to blue LED chip and the broad band centered at $560 \mathrm{~nm}$ is attributed to YAG:Ce ${ }^{3+}$. Narrow peaks around $630 \mathrm{~nm}$ are the emission lines of $\mathrm{K}_{2} \mathrm{LiGaF}_{6}: \mathrm{Mn}^{4+}$. The intensity grows with the increasing drive current. The band shapes and positions of emission peaks exhibit no remarkable change, revealing good stabilities both in color and CCT of this LED. Fig. 5(b) shows the CIE coordinate diagram of the white LED with the color point lying on the black body locus under various
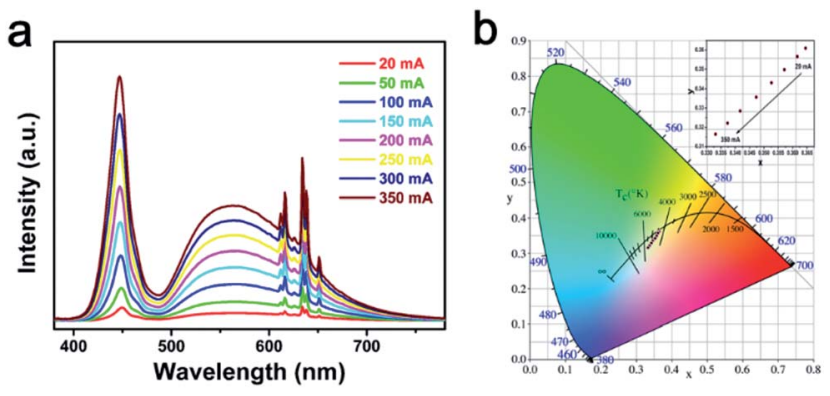

Fig. 5 (a) Electroluminescence spectra and (b) CIE chromaticity diagram of fabricated white LED under various drive currents.

drive currents. The chromaticity coordinates of them are marked in CIE 1931 color spaces and they are almost laid on the black body locus. All important photoelectric parameters for clarity are presented in Table S2. $\uparrow$ Slight variations of the color rendering index (Ra) and chromaticity coordinates are observed during the drive current range. With increasing drive current from 20 to $350 \mathrm{~mA}$, the luminous efficacy (LE) gradually decreases from 53.3 to $40.7 \mathrm{~lm} \mathrm{~W}^{-1}$, due to the monotonously decreased external quantum efficiency of the blue InGaN chip and the low quantum efficiency of $\mathrm{K}_{2} \mathrm{LiGaF}_{6}: \mathrm{Mn}^{4+}$. Commercial white LEDs only using a single YAG: $\mathrm{Ce}^{3+}$ phosphor has a low CRI, ${ }^{61}$ typically, $\mathrm{Ra}<70$. By adding $\mathrm{K}_{2} \mathrm{LiGaF}_{6}: \mathrm{Mn}^{4+}$ red phosphors, CRI is improved to 80.8. Specifically, all the R9 values are positive, which suggests good rendition of the red component.

\section{Conclusions}

In summary, a novel red emitting $\mathrm{K}_{2} \mathrm{LiGaF}_{6}: \mathrm{Mn}^{4+}$ phosphor was synthesized by a facile cation exchange method. It exhibits a broadband excitation extending from 300 to $500 \mathrm{~nm}$ and an ideal narrow band emission centered at $632 \mathrm{~nm}$, which matches well with the UV and blue LED chips. The PL properties of the phosphors were optimized by varying the $\mathrm{Mn}^{4+}$ concentration, reaction times, and reaction temperature. For changing the luminescent center ions, the emission intensity of $\mathrm{K}_{2} \mathrm{LiGaF}_{6}$ :$\mathrm{Mn}^{4+}$ is much higher than $\mathrm{K}_{2} \mathrm{LiAlF}_{6}: \mathrm{Mn}^{4+}$. It is a good way to adjust PL properties of luminescent materials. Moreover, $\mathrm{K}_{2}$ $\mathrm{LiGaF}_{6}: \mathrm{Mn}^{4+}$ exhibits an excellent thermal quenching behavior and color stability over the temperature range of 300-500 K. The $\mathrm{Ra}$, CCT and luminous efficiency of fabricated WLED are 79.5, $4363 \mathrm{~K}$ and $53.3 \mathrm{~lm} \mathrm{~W}^{-1}$, respectively. All these results imply that the $\mathrm{K}_{2} \mathrm{LiGaF}_{6}: \mathrm{Mn}^{4+}$ red emitting phosphor has potential applications in white LEDs.

\section{Acknowledgements}

This study was financially supported by the "973" programs (2014CB643801), the NSFC (51572302 and 21271191), the Joint Funds of the National Natural Science Foundation of China and Guangdong Province (U1301242), Teamwork Projects of Guangdong Natural Science Foundation (S2013030012842), Guangdong Science \& Technology Project (2015B090926011) and the Natural Science Foundation of Guangdong Province 
(2014A030313114). M. G. Brik thanks the supports from National Recruitment Program of High-end Foreign Experts (Grant No. GDW20145200225), Programme for the Foreign Experts offered by Chongqing University of Posts and Telecommunications, European Regional Development Fund (TK141), and Ministry of Education and Research of Estonia, Project PUT430.

\section{References}

1 E. F. Schubert, T. Gessmann and J. K. Kim, Light emitting diodes, Wiley Online Library, 2005.

2 S. Pimputkar, J. S. Speck, S. P. DenBaars and S. Nakamura, Nat. Photonics, 2009, 3, 180-182.

3 H. A. Höppe, Angew. Chem., Int. Ed., 2009, 48, 3572-3582.

4 C. Feldmann, T. Jüstel, C. R. Ronda and P. J. Schmidt, Adv. Funct. Mater., 2003, 13, 511-516.

5 J. He, Y. He, Y. Chen, B. Lei, H. Zhang, J. Zhuang, M. Zheng and Y. Liu, RSC Adv., 2016, 6, 104724-104730.

6 C. Zhao, Z. Xia and M. Li, RSC Adv., 2014, 4, 33114-33119.

7 S. Ye, F. Xiao, Y. X. Pan, Y. Y. Ma and Q. Y. Zhang, Mater. Sci. Eng., $R, 2010,71,1-34$.

8 E. F. Schubert and J. K. Kim, Science, 2005, 308, 1274-1278.

9 C. C. Lin and R.-S. Liu, J. Phys. Chem. Lett., 2011, 2, 12681277.

10 C. C. Lin, A. Meijerink and R. S. Liu, J. Phys. Chem. Lett., 2016, 7, 495-503.

11 T. Wang and H. Li, Chem.-Eur. J., 2016, 22, 12400-12405.

12 J. Liu, B. Xu, C. Song, H. Luo, X. Zou, L. Han and X. Yu, CrystEngComm, 2012, 14, 2936-2943.

13 Y. Chen, J. Wang, C. Liu, X. Kuang and Q. Su, Appl. Phys. Lett., 2011, 98, 081917.

14 O. Milosevic, L. Mancic, M. E. Rabanal, J. M. Torralba, B. Yang and P. Townsend, J. Electrochem. Soc., 2005, 152, G707-G713.

15 J.-G. Li, X. Li, X. Sun and I. Takamasa, J. Phys. Chem. C, 2008, 112, 11707-11716.

16 M. Peng, X. Yin, P. A. Tanner, M. G. Brik and P. Li, Chem. Mater., 2015, 27, 2938-2945.

17 Y. Li, D. Dai and S. Cai, J. Chin. Rare Earth Soc., 1996, 14, 1619.

18 G. A. Kumar, D. X. Liu, Y. Tian, M. G. Brik and D. K. Sardar, Opt. Mater., 2015, 50, 199-203.

19 C. Guo, D. Huang and Q. Su, Mater. Sci. Eng., B, 2006, 130, 189-193.

20 R.-J. Xie, N. Hirosaki, K. Sakuma, Y. Yamamoto and M. Mitomo, Appl. Phys. Lett., 2004, 84, 5404-5406.

21 X. Piao, K.-i. Machida, T. Horikawa, H. Hanzawa, Y. Shimomura and N. Kijima, Chem. Mater., 2007, 19, 4592-4599.

22 T.-C. Liu, B.-M. Cheng, S.-F. Hu and R.-S. Liu, Chem. Mater., 2011, 23, 3698-3705.

23 Y. Q. Li, N. Hirosaki, R. J. Xie, T. Takeda and M. Mitomo, Chem. Mater., 2008, 20, 6704-6714.

24 M.-H. Du, J. Mater. Chem. C, 2014, 2, 2475-2481.

25 M. Brik, S. Camardello and A. Srivastava, ECS J. Solid State Sci. Technol., 2015, 4, R39-R43.
26 M. H. Du, J. Lumin., 2015, 157, 69-73.

27 H.-D. Nguyen and R.-S. Liu, J. Mater. Chem. C, 2016, 4, 10759-10775.

28 M. G. Brik and A. M. Srivastava, J. Lumin., 2013, 133, 69-72.

29 Z. Zhou, N. Zhou, M. Xia, M. Yokoyama and H. T. Hintzen, J. Mater. Chem. C, 2016, 4, 9143-9161.

30 D. Chen, Y. Zhou and J. Zhong, RSC Adv., 2016, 6, 8628586296.

31 S. Adachi and T. Takahashi, J. Appl. Phys., 2008, 104, 023512. 32 T. Takahashi and S. Adachi, J. Electrochem. Soc., 2008, 155, E183-E188.

33 Y. Arai and S. Adachi, J. Lumin., 2011, 131, 2652-2660.

34 Z. Wang, Y. Liu, Y. Zhou, Q. Zhou, H. Tan, Q. Zhang and J. Peng, RSC Adv., 2015, 5, 58136-58140.

35 Z. Wang, Y. Zhou, Y. Liu, Q. Zhou, L. Luo, H. Tan, Q. Zhang, G. Chen and J. Peng, RSC Adv., 2015, 5, 82409-82414.

36 M. Takarkhede, R. R. Patil and S. V. Moharil, Study of photoluminescence in $\mathrm{ABSiF}_{6}: \mathrm{Mn}^{4+} \quad(A=K, \quad B=\mathrm{Na}, \quad \mathrm{Cs})$ phosphor, AIP Publishing, 2016, vol. 1728, p. 020441.

37 L. Xi, Y. Pan, S. Huang and G. Liu, RSC Adv., 2016, 6, 7625176258.

38 W.-L. Wu, M.-H. Fang, W. Zhou, T. Lesniewski, S. Mahlik, M. Grinberg, M. G. Brik, H.-S. Sheu, B.-M. Cheng, J. Wang and R.-S. Liu, Chem. Mater., 2017, 29, 935-939.

39 X. Jiang, Z. Chen, S. Huang, J. Wang and Y. Pan, Dalton Trans., 2014, 43, 9414-9418.

40 Q. Zhou, Y. Zhou, Y. Liu, L. Luo, Z. Wang, J. Peng, J. Yan and M. Wu, J. Mater. Chem. C, 2015, 3, 3055-3059.

41 X. Gao, Y. Song, G. Liu, X. Dong, J. Wang and W. Yu, Dalton Trans., 2016, 45, 17886-17895.

42 R. Hoshino, T. Nakamura and S. Adachi, ECS J. Solid State Sci. Technol., 2016, 5, R37-R43.

43 Y. Pan, Z. Chen, X. Jiang, S. Huang, M. Wu and A. Srivastava, J. Am. Ceram. Soc., 2016, 99, 3008-3014.

44 Y. Zhou, Q. Zhou, Y. Liu, Z. Wang, H. Yang and Q. Wang, Mater. Res. Bull., 2016, 73, 14-20.

45 G. Mo, W. Wang, K. Wang, G. Wen, M. Zhu and J. Wang, J. Mater. Sci., 2017, 28, 8155-8159.

46 H. Zhu, C. C. Lin, W. Luo, S. Shu, Z. Liu, Y. Liu, J. Kong, E. Ma, Y. Cao, R. S. Liu and X. Chen, Nat. Commun., 2014, $5,4312$.

47 Y. Zhu, L. Huang, R. Zou, J. Zhang, J. Yu, M. Wu, J. Wang and Q. Su, J. Mater. Chem. C, 2016, 4, 5690-5695.

48 L. Chen, X. Deng, E. Zhao, X. Chen, S. Xue, W. Zhang, S. Chen, Z. Zhao, W. Zhang and T.-S. Chan, J. Alloys Compd., 2014, 613, 312-316.

49 E. Song, J. Wang, J. Shi, T. Deng, S. Ye, M. Peng, J. Wang, L. Wondraczek and Q. Zhang, ACS Appl. Mater. Interfaces, 2017, 9, 8805-8812.

50 Y. Jin, M. H. Fang, M. Grinberg, S. Mahlik, T. Lesniewski, M. G. Brik, G. Y. Luo, J. G. Lin and R. S. Liu, ACS Appl. Mater. Interfaces, 2016, 8, 11194-11203.

51 L. L. Wei, C. C. Lin, Y. Y. Wang, M. H. Fang, H. Jiao and R. S. Liu, ACS Appl. Mater. Interfaces, 2015, 7, 10656-10659. 52 Y. K. Xu and S. Adachi, J. Appl. Phys., 2009, 105, 013525.

53 Y. K. Xu and S. Adachi, J. Electrochem. Soc., 2011, 159, E11E17. 
54 C. Liao, R. Cao, Z. Ma, Y. Li, G. Dong, K. N. Sharafudeen, J. Qiu and J. Heo, J. Am. Ceram. Soc., 2013, 96, 3552-3556.

55 Y. Li, Y.-Y. Li, K. Sharafudeen, G.-P. Dong, S.-F. Zhou, Z.-J. Ma, M.-Y. Peng and J.-R. Qiu, J. Mater. Chem. C, 2014, 2, 2019-2027.

56 L. Huang, Y. Zhu, X. Zhang, R. Zou, F. Pan, J. Wang and M. Wu, Chem. Mater., 2016, 28, 1495-1502.

57 T. T. Deng, E. H. Song, J. Sun, L. Y. Wang, Y. Deng, S. Ye, J. Wang and Q. Y. Zhang, J. Mater. Chem. C, 2017, 5, 2910-2918.
58 X. Zhang, J. Wang, L. Huang, F. Pan, Y. Chen, B. Lei, M. Peng and M. Wu, ACS Appl. Mater. Interfaces, 2015, 7, 10044-10054.

59 R. Shi, J. Xu, G. Liu, X. Zhang, W. Zhou, F. Pan, Y. Huang, Y. Tao and H. Liang, J. Phys. Chem. C, 2016, 120, 4529-4537.

60 X. Zhang, Y. T. Tsai, S. M. Wu, Y. C. Lin, J. F. Lee, H. S. Sheu, B. M. Cheng and R. S. Liu, ACS Appl. Mater. Interfaces, 2016, 8, 19612-19617.

61 A. Birkel, K. A. Denault, N. C. George, C. E. Doll, B. Héry, A. A. Mikhailovsky, C. S. Birkel, B.-C. Hong and R. Seshadri, Chem. Mater., 2012, 24, 1198-1204. 